\title{
NARRATIVAS DE SI NA INICIAÇÃO À DOCÊNCIA: O PIBID COMO ESPAÇO E TEMPO FORMATIVOS
}

\author{
SILVA, Fabrício Oliveira $\mathrm{da}^{{ }^{1 *}} ;$ RIOS, Jane Adriana Vasconcelos Pacheco ${ }^{{ }^{* *}}$ \\ ${ }^{1}$ Universidade do Estado da Bahia \\ faolis@ig.com.br* \\ jhanrios1@yahoo.com.br ${ }^{* *}$
}

\section{RESUMO}

Analisou-se a trajetória de iniciação à docência de uma bolsista do Programa Institucional de Bolsas de Iniciação à Docência na Universidade do Estado da Bahia, objetivando compreender como o programa faculta a inserção do licenciando em Letras na dinâmica das práticas educativas. Apresentaram-se os objetivos do programa, a organização e as experiências da iniciação à docência narradas pela bolsista, refletindo-se sobre a sua trajetória formativa, as experiências vividas numa dupla dimensão do referido

programa: a de se constituir como uma categoria de tempo formativo, bem como de lócus em que a iniciação à docência produz sentidos do ser professor pela complexidade e dinâmica da realidade escolar. Optou-se pela abordagem (auto)biográfica com base em autores que estudam a temática. $O$ estudo mostrou que o mencionado programa favoreceu a inserção da licencianda no contexto do cotidiano da escola, o que possibilita desenvolvimento de experiências para o ensino de Língua Portuguesa.

PALAVRAS-CHAVE: Pibid. Formação. Práticas educativas. Ensino. Narrativas.

\section{NARRATIVE OF ONESELF IN THE INITIATION TO TEACHING:}

\section{THE PIBID AS SPACE AND TIME FORMATION}

\begin{abstract}
The initiation trajectory was studied by a scholarship holder of the Institutional Scholarship Program at the State University of Bahia, aiming to understand how the program allows the insertion of the licenciando in Letters in the dynamics of educational practices. The objectives of the program, the organization and the experiences of the initiation to teaching were described by the scholarship holder, reflecting on their formative trajectory, the experiences lived in a double dimension of the said
\end{abstract}

program: to be constituted as a category of formative time, as well as of locus in which the initiation to the teaching produces senses of being a teacher by the complexity and dynamics of the school reality. We opted for the (auto) biographical approach based on authors who study the theme. The study showed that the mentioned program favored the insertion of the licencianda in the context of the daily life of the school, which allows the development of experiences for the teaching of Portuguese Language.

\section{NARRATIVAS DE SI MISMO EN LA INICIACIÓN A LA ENSEÑANZA: \\ EL PIBID COMO ESPACIO Y TIEMPO DE FORMACIÓN}

\section{RESUMEN}

Se analizó la trayectoria de iniciación a la docencia de una becaria del Programa Institucional de Becas de Iniciación a la Docencia en la Universidad del Estado de Bahía, con el objetivo de comprender cómo el programa faculta la inserción del licenciando en Letras en la dinámica de las prácticas educativas. Se presentaron los objetivos del programa, la organización y las experiencias de la iniciación a la docencia narradas por la becaria, reflexionándose sobre su trayectoria formativa, las experiencias vividas en una doble dimensión de dicho programa: la de constituirse como una categoría de tiempo formativo, así como de locus en que la iniciación a la docencia produce sentidos del ser profesor por la complejidad y dinámica de la realidad escolar. Se optó por el enfoque (auto)biográfico con base en autores que estudian la temática. El estudio mostró que el programa mencionado favoreció la inclusión de licencianda en el contexto de la rutina de la escuela, lo que permite a las experiencias de desarrollo de la enseñanza del portugués.

PALABRAS CLAVE: Pibid. Formación. Prácticas educativas. Enseñanza. Narrativas. 


\section{INTRODUÇÃO}

O conhecimento de si revela a essência da vida, que antes de ser pensada, precisa ser vivida. Clarice Lispector (1998) já nos dizia que não é necessário entender a vida, pois "vivê-la ultrapassa todo o entendimento". Assim só podemos compreender a vida se a vivermos intensamente, no movimento da cotidianidade, temporalidade e espontaneidade. É nesse tripé que a ideia de trajetória, neste trabalho, se fundamenta, visto que se constitui por uma essência de movimentos que a vida nos proporciona e que vão sendo compreendidos na medida em que vamos produzindo sentidos para cada movimento vivido. Esses movimentos podem, são e devem ser compreendidos pelo próprio sujeito, quando este para e o reconstrói por meio de narrativas que vão tecendo em outro tempo e forma os sentidos de uma vida vivida e ressignificada.

Ainda que a trajetória de um sujeito possa ser determinada pela sociedade e pela cultura (SILVA, 2017), os acontecimentos e os encontros são em grande parte imprevisíveis, o que dá sentido aos aspectos interpretativos de uma narrativa, momento em que o próprio sujeito que narra atribui um novo sentido a experiência vivida. Isso sugere que não se pode antecipar qual o peso que as experiências terão durante a trajetória de cada sujeito, principalmente, por não haver condições de se saber como as experiências são vivenciadas pelo sujeito, salvo pela produção de sua própria narrativa, em que se volta para si e por meio dela reconstrói-se o vivido em um novo tempo.

Neste sentido, discorremos neste trabalho sobre algumas reflexões a respeito do processo de produção de experiências de formação construídas pelo Programa Interinstitucional de Bolsas de Iniciação à Docência (Pibid) com uma bolsista, estudante do curso de Letras da Universidade do Estado da Bahia (UNEB). É neste cenário, que a pesquisa objetivou analisar como a discente, durante a sua formação acadêmica, percebe e narrativiza sua formação e concebe a aprendizagem da docência a partir das experiências vivenciadas no ambiente escolar e como as relaciona à formação em diferentes tempos, transversalizada pela compreensão de si. Neste aspecto, emerge a possibilidade de analisar como ocorre a constituição identitária de um professor em formação inicial.

Algumas questões emergiram na pesquisa e nortearam as reflexões apresentadas neste artigo. Disso, buscamos entender, dentre outras, como o conceito de si é construído pela 
bolsista? Como a realidade escolar se relaciona ao processo formação do docente? De que maneira a bolsista constrói o conhecimento sobre a docência de Língua Portuguesa?

O estudo se originou da pesquisa com a licencianda do curso de Letras, bolsista do Pibid, do período 2015/2016. Foi feita uma entrevista narrativa com a licencianda, por meio da qual se buscou analisar como a estudante desvela sentidos sobre o programa, experienciado na realidade escolar. Pela viabilidade de se tomar a própria narrativa como elemento de estudos das trajetórias de formação da licencianda, tornou-se central, para este estudo, a ideia de compreender como a trajetória de formação de um sujeito é tecida pelas experiências que logra, dada a sua inserção e participação em condições reais e complexas da docência que desenvolve um professor na escola básica ao ensinar Língua Portuguesa.

Assim, a compreensão de si, revelada por meio das narrativas (auto)biográficos, permitiu analisar como o Pibid a insere no espaço escolar, oportunizando a produção de experiências formativas transversalizadas pelo tempo cronológico de organização das atividades do ensino de língua na escola, assim como pelo tempo do sujeito, tempo psicológico em que as aprendizagens se desenvolvem em outro ritmo, nascidas a partir da subjetividade de cada um.

\section{TRAMAS DA TESSITURA METODOLÓGICA}

Esta pesquisa ancorou-se na abordagem (auto)biográfica na perspectiva descrita por Souza (2006), de defender a ideia de que esta abordagem está diretamente relacionada a uma concepção de educação construída ao longo da vida de um sujeito, valorizando o seu processo de formação e os sentidos que se constroem pelas trajetórias de formação. Por meio desta metodologia, é possível, durante o processo de realização da pesquisa, "[...] instaurar-se um movimento de investigação-formação ao enfocar o processo de conhecimento e de formação que se vincula ao exercício de consciência, por parte do sujeito, das itinerâncias e aprendizagens ao longo da vida" (SOUZA, 2006, p. 45).

Defendemos que toda narrativa reflete uma práxis humana, daí sua relação com a fenomenologia, que concebe as ações do homem como eixo de observação e de interpretação da vida cotidiana. A grande contribuição da abordagem (auto)biográfica é possibilitar ao sujeito o conhecimento de si que se fundamenta em um modelo epistemológico concebido a partir da 
produção de narrativas que, entre outros papeis, têm a função de reconstruir o momento já vivido, em um outro tempo e dimensão estrutural, que já não é mais a vivida, e sim a narrada. Segundo Josso (2004), a abordagem do método (auto)biográfico assinala um processo de mudança de perspectiva do pesquisador, por meio do apuramento de metodologias de investigação-ação-formação, articuladas à construção de uma história de vida. Além disso, demarca a contribuição de um conhecimento que abrange a formação, a auto formação e elucidando as características de um público específico.

\footnotetext{
É interessante observar que a introdução do método (auto)biográfico no domínio das ciências da educação não provocou grandes debates teóricos e epistemológicos; menos impregnadas do que as outras ciências sociais por uma perspectiva positivista, as ciências da educação compreenderam de modo algo intuitivo a importância do método (auto)biográfico, que se veio a revelar não apenas um instrumento de investigação mas também, (e sobretudo) um instrumento de formação. (NÓVOA; FINGER, 2014, p. 22).
}

Nesta pesquisa, utilizamos a abordagem (auto)biográfica não só como um importante elemento de investigação das trajetórias formativas da licencianda em Letras, mas sobretudo como um instrumento de formação. Acreditamos que ao produzir narrativas sobre si, a estudante desta pesquisa se inseriu numa condição de reconstruir e de refletir alguns momentos por ela vividos, fazendo aflorar os significados que o ato de narrar é capaz de promover, vez que ele se dá a partir da ideia de que é preciso fazer escolhas sobre o que, quando e como um momento deve ser reconstruído. E é nessa reconstrução que produzimos sentidos, percebendo a distinção entre duas dimensões temporais em que a experiência é ressignificada: o tempo em que ela ocorreu; e um tempo em que ela foi reconstruída pela linguagem. O movimento formativo que se pode verificar na abordagem (auto)biográfica permitiu à colaborada tomar a linguagem como um cenário reflexivo, por meio do qual deu forma e sentido às suas experiências, numa condição perene de produção de conhecimento sobre si.

O ponto de partida de uma pesquisa (auto)biográfica é sempre a vida do sujeito, que passa a ser narrada e vivenciada em uma outra dimensão temporal, que não aquela em que originalmente os fatos ocorreram (SOUZA, 2006). É tomada pela dimensão dos processos formativos e indicações sobre a realidade social que devem ser buscadas inicialmente nela, isto é, na fusão da sua subjetividade com a estrutura social.

Educação \& Formação, Fortaleza, v. 3, n. 8, p. 57-74, maio/ago. 2018

DOI: http://dx.doi.org/

http://seer.uece.br/redufor 
É neste sentido que o processo de formação e de iniciação à docência em si é uma aventura. Importa e muito, para os que trabalham com o método, se as experiências podem ou não se transformar em autoconsciência. Em outras palavras, passar pela reflexão, pela elaboração, pela interpretação. E essa interpretação está necessariamente articulada com uma temporalidade. Segundo Ereben (1996, p. 73)

\begin{abstract}
A essência do método biográfico consiste, mais precisamente, em investigar a forma como a autoconsciência de terceiros é empregada para produzir sua própria autoformação. $O$ sujeito humano pode interpretar a si mesmo somente através da ação de interpretar os sinais captados no mundo que o circunda. Não existe qualquer noção de si mesmo ou de identidade que seja transmitida geneticamente. Estamos unidos ao passado e ao futuro, visto que é uma característica constitutiva da mente humana possuir uma memória e a capacidade de projeção. Assim, o passado está sempre necessariamente ligado a um futuro e, quando este chegar, o passado já estará - desta mesma forma - ligado a um outro novo futuro.
\end{abstract}

Isso sugere que o método (auto)biográfico possui um aspecto intra-reflexivo que o sujeito leva em conta ao falar de si. Daí nesse estudo em que se pretendeu, entre outras questões, compreender como a inserção de uma licencianda em Letras no ambiente de práticas educativas do ensino de Língua Portuguesa favorece a produção de experiências do ser professor de língua materna na escola. Assim, o estudo permitiu, também, analisar o processo de produção identitária da licencianda a partir das experiências no Pibid. Para isso, foi importante partir da condição se tomar a narrativa como elemento que desvela as reflexões que a bolsista fez ao vivenciar a escola num tempo e num espaço de formação real de atuação do professor, em que se experiencia as práticas educativas do ensino de língua, produzidas na complexidade relacional entre diferentes sujeitos que atuam na escola.

\title{
3 O PIBID COMO ESPAÇO E TEMPO FORMATIVOS
}

O programa foi lançado em sua primeira versão em dezembro de 2007, através da Lei no 11.502, de 11 de julho de 2007, por meio de um edital que tinha como principal objetivo atender às demandas de formação de licenciandos nas áreas de Ciências Exatas e Naturais. A justificativa para o desenvolvimento do programa nessas duas áreas se deu por conta, segundo o Censo escolar INEP/MEC do mesmo ano, de uma baixa procura pelos cursos de licenciatura, principalmente nas áreas de Química, Física, Matemática e Biologia. A perspectiva inicial do

Educação \& Formação, Fortaleza, v. 3, n. 8, p. 57-74, maio/ago. 2018

DOI: http://dx.doi.org/

http://seer.uece.br/redufor 
Ministério de Educação com o programa era o de atrair os jovens para que cursassem licenciatura e tivessem por ela um adequado processo formativo. A partir de 2009, por meio do Edital Capes/DEB no 02/2009, o Ministério fez progredir o programa, publicando editais em todas as áreas do conhecimento.

No cenário de políticas públicas de fomento à educação, na primeira e início da segunda década do século XXI, o Pibid constitui parte das ações do governo federal de Desenvolvimento da Educação, que tiveram início em 2001. Assim o programa integra o conjunto de reformas iniciadas nesse ano, com a promulgação de Diretrizes Nacionais para a Formação, em nível superior, de professores para a Educação Básica (Parecer CNE/CP no 009/2001 e Resolução CNE/CP no 1/2002. Nesta direção, o Pibid surge de um conjunto de objetivos que primavam por combater os problemas centrais relacionados à formação e à valorização dos professores de Educação Básica em todo o território nacional.

Um dos objetivos do Pibid na UNEB é a elevação da qualidade das ações acadêmicas voltadas à formação inicial de professores nos cursos de licenciatura. Assim com a inserção dos licenciandos no cotidiano de escolas da rede pública de educação, o programa promove a integração entre Educação Superior e Educação Básica, permitindo ao estudante de Letras inserirem-se em práticas reflexivas do ensino de língua, que lhe serão base para o exercício futuro de sua profissão.

Nesta lógica, Semântica ${ }^{1}$ numa compreensão de si e de sua trajetória no programa, produz uma narrativa reflexiva, reverberada pelo que defende Delory-Momberger (2012) ao considerar que a dimensão formativa do método (auto)biográfico evoca algumas questões sobre a natureza das operações que realiza sobre o vivido, no caso em tela a participação de Semântica em práticas educativas do ensino de Língua Portuguesa na escola. Desta condição formativa, a bolsista compreende que o programa é uma oportunidade de produzir nela experiências e reflexões sobre o trabalho docente do professor de Língua Portuguesa. Isso sugere que ela passa a considerar a inserção no cotidiano da escola como forma de instauração de saberes sobre a

\footnotetext{
1 Por sugestão da própria bolsista de Iniciação, optou-se por utilizar um pseudônimo, escolhido por ela mesma em referência a uma parte do estudo gramatical de que ela gosta muito. Assim, como ela se diz ser uma pessoa de sentidos, informa que queria ser chamada de semântica, exatamente por ser a parte da gramática destinada ao estudo dos sentidos das palavras.
}

Educação \& Formação, Fortaleza, v. 3, n. 8, p. 57-74, maio/ago. 2018

DOI: http://dx.doi.org/

http://seer.uece.br/redufor 
docência, aproximando-se das discussões de Possenti (2000) quando o autor reflete sobre alguns princípios das razões pelas quais (não) se deve ensinar gramática na escola. Diz-nos Semântica:

\begin{abstract}
No meu contato com o Pibid, percebo algumas práticas docentes no ensino de Língua Portuguesa que seriam fundamentais para minha formação que eu utilizaria e outras que não utilizaria, por exemplo, no ensino de gramática uma coisa que eu experienciei bastante durante esse ano foi o trabalho com a gramática contextualizada e em certo momento o trabalho com ela não contextualizada, mas, uma gramática seca, isso eu não utilizaria na mina prática enquanto docente porque ao observar como foi realizada aquelas aulas em que os alunos iriam através de frases identificar algumas categorias gramaticais percebi que eles tinham muita dificuldade, porque eles ficavam apreensivos já em falar que seria trabalhado gramática em sala de aula. (Semântica, Entrevista Narrativa, fragmento 1, 2016).
\end{abstract}

Saber "o quê" e "como" ensinar, considerando os aspectos do ensino de língua, só se aprende a partir da interação com o outro no ambiente escolar e não por manuais de ensino de língua, muito menos por domínio de concepções teóricas do pensamento linguístico. É dessa concepção que a bolsista considera a sua participação no programa como forma de dar a ela a condição de estabelecer relações de escolhas metodológicas das quais lançaria mão ou não para trabalhar o conteúdo gramatical com os estudantes. Essa postura sugere que ela instaura uma reflexão de si em si, a partir das experiências produzidas no "chão da escola" de que o ensino de Língua Portuguesa, no caso em tela, de gramática, deve ser contextual e deve partir da necessidade que o sujeito aprendente apresenta.

Essa condição de compreender como a sua história no programa se entrecruza com seu processo formativo, faz Semântica gestar para si mesma um processo de formação, em que ela passa a ser a grande protagonista do ato formativo, vez que é ela, a partir de suas subjetividades, quem está em melhor condição de estabelecer valor às experiências metodológicas do ensino de língua vividas pelo programa, na realidade da escola. Esse é, talvez, o grande movimento formativo em que a licencianda se insere, ao tomar as suas próprias experiências como elementos balizadores do seu desenvolvimento profissional, ainda que de iniciação à docência. Tal posição, ancora-se no que Josso (2004, p. 48) considera ao defender que:

\footnotetext{
Falar das próprias experiências formadoras é, pois, de certa maneira, contar a si mesmo a própria história, as suas qualidades pessoais e socioculturais, o valor que se atribui ao que é 'vivido' na continuidade temporal do nosso ser psicossomático. Contudo, é também um modo de dizermos que, neste continuum temporal, algumas vivências têm uma intensidade particular que se impõe a nossa consciência e delas extrairemos as informações úteis as nossas transações conosco próprios e/ou com o nosso ambiente humano e natural.
}

Educação \& Formação, Fortaleza, v. 3, n. 8, p. 57-74, maio/ago. 2018

DOI: http://dx.doi.org/

http://seer.uece.br/redufor 
O valor do que é vivido é o valor das experiências que se logram na realidade da escola, do ensino de língua oportunizado pelo programa. No entanto, pela própria narrativa da bolsista, vê-se que o processo de sua formação em nível de licenciatura foi potencializado pelas experiências vivenciadas no Pibid, o que aponta para o peso da temporalidade no processo de formação do sujeito. Não se trata apenas de estar no tempo da escola, no chronos, em que as atividades e movimentos são marcados pelo relógio, mas também na imersão que o sujeito faz em outro tempo, kairós, tempo das experiências e produção de ritmos internos que se distinguem de sujeito a sujeito e de situação a situação. Portanto, inserir-se num movimento temporal complexo, em que se considera o tempo da escola e do sujeito, faz Semântica compreender que a sua participação no programa the deu condições de desenvolvimento de processos cognitivos do fazer docente, que talvez não aconteça com outros tantos licenciandos, que por ventura não tenham passado pela experiência do programa. Assim, Semântica, em sua compreensão sobre si e sobre o Pibid, diz-nos:

\begin{abstract}
Então, a minha formação enquanto profissional foi muito mais complementada a partir da participação desse projeto, porque a meu ver os alunos que não tem a oportunidade de participar do projeto Pibid durante sua formação ele sai com alguma lacuna, porque ele não vivenciou aquela prática, porque ele não teve naquele meio escolar, e isso quando ele chegar a executar em si a sua profissão enquanto professor ele vai sentir algumas dificuldades, porque aquilo tudo vai ser muito novo, aquilo tudo vai ser é... vai necessitar ser amadurecido, e até isso ser amadurecido ele vai passar por algumas dificuldades, e o estudante de letras que sai do projeto Pibid para a sua vida profissional ele já não vai ter tantas dificuldades porque ele já vivenciou, porque ele já teve aquela prática ali em sala de aula e ele vai saber como resolver alguns eventuais problemáticas que aparecer ali na sua sala de aula, e também vai saber como lidar com a coordenação, com os professores, com a direção, como é... executar a parte mais burocrática que é da caderneta, que é da correção de provas, das notas e tudo, então esse projeto tem contribuído muito para minha formação enquanto profissional. (Semântica, Entrevista narrativa, fragmento 2, 2016).
\end{abstract}

Ademais, de se pensar nos valores de se abordar o vivido, a compreensão de Semântica sobre a formação de professores de Língua Portuguesa aponta para a existência de uma problemática de que o professor tem se formado e pouco, durante a sua formação, vivenciado o cotidiano da escola e conhecido as questões inerentes à docência na Educação Básica. Esta é a lógica pela qual o Pibid é visto pelo MEC, e consequentemente por Semântica ao considerar que seu processo formativo se dá na realidade educacional da escola básica, como um lócus de produção de experiências que alarga as possibilidades de inserção do sujeito na escola, potencializando a sua

Educação \& Formação, Fortaleza, v. 3, n. 8, p. 57-74, maio/ago. 2018

DOI: http://dx.doi.org/

http://seer.uece.br/redufor 
formação. E disto pode-se inferir que os diferentes tempos formativos se constituem como elementos vitais para a promoção de desenvolvimento dos saberes docente. A escola passa a ser um lugar de formação privilegiado neste processo, na medida em que faculta à bolsista estar nela e vivenciá-la em sua dinâmica real de organização e estruturação do trabalho pedagógico.

A problemática da formação de professores fora do âmbito do Pibid e pela lógica reflexiva de Semântica tem algumas raízes e fundamentos, tais como:

I) A formação do professor da Educação Básica não se faz na realidade da escola, pois os licenciandos só se inserem pontualmente nela em alguns momentos, como no caso do estágio;

II) A formação dos licenciandos nem sempre considera os diferentes tempos e ritmos de aprendizagem do sujeito;

III) A licenciatura em Letras não tem oportunizado o desenvolvimento de competências pedagógicas inerentes ao professor de língua materna. Sabe-se o que ensinar, mas nem sempre como ensinar e para quem ensinar, pois a realidade do ensino é desconhecida;

IV) Quem ensina deve, também, aprender o que ensinar na relação com quem se ensina. $\mathrm{Na}$ licenciatura essa não tem sido uma realidade, pois o cotidiano escolar, lugar das relações e desenvolvimento das experiências não é experienciado pelos licenciandos.

O que surge pela compreensão de Semântica ao considerar que sua formação universitária não dá condições plenas dela, fora do Pibid, ter desenvolvido os saberes da docência do professor de língua materna, é uma problemática que está discutida e analisada em muitos estudos sobre o papel do curso de Letras na formação dos professores de Língua Portuguesa. A evidência de pouca ênfase nos cursos sobre a discussão dos saberes da docência justifica-se pela vasta produção dos saberes linguísticos que, nos últimos anos, surgiram em novas teorias e categorias. A necessidade de ter um currículo que dê conta do conhecimento de toda essa produção teórica da linguagem fez afastar do palco formativo do professor de língua materna as concepções da docência. Autores como Miranda (2000, p. 203) ressaltam que é "[...] preciso repensar com urgência os cursos de Letras". Nos cursos, "[...] os currículos e suas grades curriculares se assentam em concepções tradicionais de linguagem" (OLIVEIRA, 2003). Em muitos currículos não há evidência de conhecimento tácito das orientações contidas nos PCNs a respeito do ensino da língua e das

Educação \& Formação, Fortaleza, v. 3, n. 8, p. 57-74, maio/ago. 2018

DOI: http://dx.doi.org/

http://seer.uece.br/redufor 
propostas existentes ali (REINALDO, 2000). Além disso, os licenciandos não têm vivenciado a escola como palco de sua formação, a exceção dos momentos de realização estágios, e de alguns poucos estudantes que, de 2009 para cá, tiveram a oportunidade de estar no Pibid.

Oliveira (2004, p. 3), numa pesquisa que focaliza a formação inicial de professores de língua materna a partir de entrevistas realizadas com licenciandos do curso de Letras de algumas instituições públicas, chama-nos a atenção para o fato de que a maioria dos licenciandos "[...] reconhece como disciplinas fundamentais à sua formação aquelas relacionadas à área da Linguística e da Língua Portuguesa". Os dados do estudo de Oliveira (2004) revelam que muitos estudantes informam que desconhecem os textos integrais dos PCNs, relacionados ao ensino de Língua Portuguesa nos níveis de Ensino Fundamental e Médio e, ainda conforme nos assevera este autor, "[...] o que é mais grave, não conseguem estabelecer relações entre os conteúdos neles apresentados e aqueles de sua formação".

De fato, que o processo de formação do educador no curso de Letras ainda prima pela ideia da instrumentalização de um pesquisador da linguística ou da literatura. Esse fato é sinalizado nos estudos realizados por Oliveira (2003), ao enfatizar que a valorização do conhecimento técnico da linguagem no curso de Letras tem raízes pela decorrência da organização curricular destes cursos que, segundo o autor obedece a uma certa visão, ainda dominante, de que os conteúdos necessários para formar professores de língua materna são tecidos no domínio da língua, amplamente entendida como ferramenta de um como sistema estruturado e normativo.

\section{PIBID: LUGAR DA PRODUÇÃO DE EXPERIÊNCIAS FORMATIVAS DA INICIAÇÃO À DOCÊNCIA}

O Pibid surge neste contexto, fazendo com que a universidade repense o processo de formação do professor de Língua Portuguesa, dado que ele inserido na realidade escolar busca compreender constantemente mecanismos de ensino de língua que sejam produtivos e funcionais para os estudantes da Educação Básica. Essa postura significa repensar o currículo, repensar, na universidade, como a formação do professor de Letras precisa dar conta do universo da docência, englobando os saberes pertinentes ao ofício do ser professor. Um pressuposto que toda essa discussão precisa considerar refere-se à reflexão assumida pelo licenciando no Pibid, durante a sua formação, no sentido de que, ao assumir a posição de corresponsável pelo

Educação \& Formação, Fortaleza, v. 3, n. 8, p. 57-74, maio/ago. 2018

DOI: http://dx.doi.org/

http://seer.uece.br/redufor 
processo de aprendizagem, passe a compreender o papel da relação entre teoria e prática na realidade dos estudos linguísticos e literários que, como docente futuramente, irá realizar.

Consequentemente, essa posição permite ratificar os fundamentos formativos concebidos por Zeichner e Liston (1987), que defendem um processo de formação que não apenas instrumentalize os licenciandos nas habilidades da docência, mas que os prepare para um exercício de autonomia pedagógica a fim de que, quando se tornem de fato professores de Língua Portuguesa, sejam capazes de "[...] assumirem um papel mais central direcionado para o próprio empenho em tomar decisões".

Na ótica do Pibid, a imersão do licenciando no contexto da escola do cotidiano escolar tem como objetivo favorecer ao mesmo a produção de experiências formativas que permitam a ele compreender, no caso específico deste estudo, como a docência é gestada num processo de relação intersubjetiva dos sujeitos, em que são consideradas a observação, a participação e a iniciação como elementos construtores da formação que tem como objetivo futuro promover condições para um fazer docente.

Diferente do professor que já está em exercício profissional, com uma carga horária extensa e com poucas condições de produção de experiências, o licenciando encontra-se numa dimensão temporal adequada à produção destas, pois ele vive o seu tempo subjetivo, o tempo da produção de suas aprendizagens, logo o tempo em que as experiências vão sendo produzidas fora da dimensão da obrigatoriedade de cumprimento de conteúdo, fora da lógica do cumprimento de carga horária e ainda fora da lógica de atendimento de ações de políticas públicas para o ensino de Língua Portuguesa.

Nessa realidade, o licenciando acaba por se despir da obrigatoriedade para viver cada momento e cada ação na escola de forma singular e subjetiva, levando em conta as particularidades de cada ação e momento educativo do qual participa. Daí ele consegue enxergar o outro, neste caso o aluno e o professor regente, em suas necessidades reais. Assim, vê a necessidade do aluno encontrar sentido para aquilo que aprende e a do professor para aquilo que ensina. Ao estudante interessa o aprender e ao professor o ensinar e também o aprender. Mas ao licenciando, neste contexto de aluno-professor, interessa compreender como essa relação se estabelece para além dos papéis sociais previstos (e até estereotipados) para professor e aluno. É aí que o licenciando vai perceber coisas no aluno que o professor não 
percebe, bem como perceber coisas no professor que o aluno não percebe. E por que isso é possível? Exatamente porque o licenciando centra-se numa posição de observação aguçando a atenção aos detalhes da relação pedagógica desenvolvida na sala de aula, e no caso do contexto dos subprojetos, na relação ensino e aprendizagem de língua materna.

E dessa percepção ele vai constituir em si uma compreensão que se origina na intersecção de todos os saberes produzidos na formação em licenciatura, na qual o Programa está inserido. Isso cria condições para que o licenciando produza opiniões a respeito de como deve o aluno fazer para aprender e o professor para ensinar. Mas isso não quer dizer que ele tenha melhor condição de análise desses processos em relação ao professor e ao aluno, mas que está se permitindo viver um tempo de experiência que o faz perceber os efeitos e sentidos do que venha a ser a docência, sobretudo a relacionada à atividade profissional do professor de Língua Portuguesa.

Diante do exposto, podemos dizer que a experiência não nasce do trabalho laboral de ensinar português em diferentes escolas e em diferentes turmas e ciclos escolares. Ela também não nasce do acúmulo de distintas atividades que o professor realizou ao longo dos anos de trabalho. Nasce, portanto, da essência de sentido que se origina em nossa permissividade de viver plenamente uma ação, situação em um contexto específico. Nasce da nossa relação com o mundo e da entrega que fazemos dia a dia nos despindo das opiniões formadas e da ideia equivocada, como nos assevera Larrosa (2002) de que a informação é quem produz a experiência. Ter muita informação e produzir a partir delas as nossas opiniões não é garantia de que as produzimos pelas experiências desenvolvidas ao longo de uma vida. Só o exercício profissional pode não nos transformar, não mudar as nossas concepções e valores sobre o que fazemos, e nem pode garantir que estejamos em constante acompanhamento de inovações e novos saberes que se agregam à área em que atuamos. Daí a necessidade de um perene processo de formação, e como alguns defendem, por meio de cursos de atualização e de "reciclagem" como que se mercadoria técnica fossemos. Muitas coisas acontecem em nossa vida, mas as experiências são poucas e as que acontecem nos transformam, nos modificam e nos faz compreender melhor a nós mesmos.

Na docência, de um modo geral, mas também no ensino de Língua Portuguesa temos essa condição de produção de experiência que emerge da relação de ensino e aprendizagem que só se constrói na relação professor e aluno na escola. Assim, a observação do cotidiano escolar e 
as temporalidades são elementos facultadores da produção de experiências formativas no percurso de cada licenciando, vez que eles precisam se permitirem produzir experiências que Ihes sejam significativas para o processo de produção de sua identidade docente, enquanto futuros professores de língua materna.

Nesta seara, evidencia-se pelo Pibid a possibilidade de instauração de um processo formativo de professores, não apenas no sentido de produção de conhecimentos específicos de Letras, mas essencialmente de produção de saberes que contribuam para a preparação dos futuros licenciandos para o exercício da docência, numa perspectiva de profissionalismo crescente (RAMALHO, 1998). Isso sugere a criação de uma perspectiva de produção de compreensão de práticas educativas que fundamentem a reflexão sobre o trabalho com a linguagem na escola para aqueles que pretendem formarem-se professores de Português. Essa visão é compactuada por Soares (2002), que também se apresenta como uma importante voz que traz à tona os desafios presentes na formação do profissional de Letras, revelando a preocupação com o perfil de professores que as universidades têm formado na área. Desse modo, a sua inquietação é apresentada em alguns questionamentos que nos fazem pensar sobre:

Que grupos sociais estão hoje demandando a profissão de professores de Português e, para isso, frequentam as salas de aula dos cursos de Letras? Quem são estes que devemos formar como professores de Português? [...] que formação devem ter os que formam os professores? (SOARES, 2002, p. 219).

A partir desses questionamentos, é possível pensar numa concepção de que os futuros professores devem, também, ser formados na realidade da escola diante de toda a complexidade que ela apresenta, sobretudo no processo relacional com os alunos em se tratando do ensino de língua materna.

Ter passado por todo o percurso formativo do Pibid permitiu a Semântica conceber que a futura chegada à escola, como docente de fato, será marcada com o sabor de uma preparação para o exercício profissional, que dará condições ao futuro professor de já ter desenvolvido experiências e logrado o desenvolvimento de saberes da docência que nortearão a sua prática. Enfrentar dificuldades tendo conhecimento das realidades do ensino constitui-se em amplo e rico processo formativo, favorecendo perenes momentos reflexivos sobre a docência, o que implica num movimento cíclico de criação de estratégias e metodologias que dão pistas ao sujeito de

Educação \& Formação, Fortaleza, v. 3, n. 8, p. 57-74, maio/ago. 2018

DOI: http://dx.doi.org/

http://seer.uece.br/redufor 
como fazer e porque fazer o ensino de língua na escola. Isso sugere que o professor em formação logra êxito cognitivo de conhecimentos implícitos que foram produzidos nele pela dimensão das práticas educativas, a partir das quais produziu experiências do ser professor de língua materna, que se adjetivam, neste processo, de plenamente formativas. A despeito desse movimento reflexivo, diz-nos Semântica que:

\begin{abstract}
Toda essa dinâmica da escola ela vem para complementar aquilo que é visto no curso pelo estudante de Letras. Porque no curso você aprende muitas coisas teóricas como a elaboração de algumas provas, nas práticas pedagógicas a gente vê quais são os tipos de avaliação, como você deve proceder na hora de elaborar essa prova e tal, só que no projeto você tem aquele contato com a escola, e a escola vem complementar tudo aquilo que você vê na universidade. [...] E também outra coisa que eu percebo é que na escola no momento da prática que você vai ter tem muitas coisas que você não exatamente vai executar da forma que você planejou, que é no caso dos planos de aula, na universidade a gente aprende a fazer muitos planos de aula, a planejar todos os momentos, a trazer ludicidade, mas na prática você percebe que nem tudo daquilo dá certo, então ali no projeto você tá vendo de que forma você pode utilizar esses planos, quando eles precisam ser modificados, quando eles precisam ser revistos. (Semântica, Entrevista narrativa, fragmento 2, 2016).
\end{abstract}

Disso, podemos dizer que o processo de inserção de Semântica no âmbito da escola e da dinâmica do trabalho educativo já promove nela a transformação da concepção formativa do professor, que irá ao exercício laboral com uma perspectiva de produção de experiências diferente de outros que não tiveram a oportunidade de vivenciar a escola na sua dimensão real, factual e contextual. Ademais, há de se validar o fato de que as experiências na escola, vivenciadas pela discente, ocorreram na dimensão temporal de sua subjetividade, em se considerando o tempo kairós, que se processa no ritmo de aprendizagem de cada sujeito, demarcando o lugar das singularidades e pessoalidades do processo de aprendizagem. É na dimensão desse tempo que podemos entender a experiência como única, pessoal e subjetiva.

Isso aponta para o fato de que Semântica se insere num movimento de produção de experiências formativas instauradas na complexidade relacional da escola, que, como defendem Tardif, Lessard e Lahaye (1991, p. 218), “[...] a relação dos docentes com os saberes não se reduz a uma função de transmissão dos conhecimentos já constituídos, pois sua prática integra diversos saberes". Nesse sentido, a compreensão do que deverá fazer no seu exercício profissional, quando professora de fato for, surge na narrativa marcada pela condição de que a licencianda tem de mobilizar os saberes disciplinares, oriundos da formação no curso de Letras; os saberes do 
cotidiano relacional e das ideias que construiu ao longo do tempo, por ter sido aluna, do que é e do que faz um professor, os saberes curriculares de práticas educativas que são produzidas para além da escola. Todos esses saberes marcam a trajetória de formação da licencianda e dão contorno aos novos saberes que pela experiência do Pibid ela vai construindo sobre o fazer docente.

\section{CONSIDERAÇÕES FINAIS}

A narrativa produzida por Semântica, na compreensão de si revelou que o Pibid proporciona aos futuros professores a participação em experiências metodológicas, tecnológicas e práticas docentes de caráter inovador e interdisciplinar, objetivando a superação de problemas identificados no processo de ensino-aprendizagem. Além de incentivar as escolas públicas a tornarem-se protagonistas nos processos formativos dos estudantes das licenciaturas, a partir da troca de experiências entre os supervisores, professores da Educação Básica, com os bolsistas que refletem as orientações e a condução pedagógica que cada professor-supervisor, que é um professor de língua materna, lhe oferta no desenvolvimento de suas ações na escola.

Por meio da abordagem (auto)biográfica foi possível compreender como a trajetória de formação docente é construída e vista pelo sujeito, na sua relação com o mundo da iniciação à docência que Ihe é oportunizado pelo Pibid. Acreditamos, portanto, que por meio de análise de narrativas foi possível depreender os sentidos que a licencianda atribuiu à experiência formativa que se consolida em diferentes tempos e espaços de formação, quando sua efetiva participação no Pibid. Falar de si e poder refletir sobre os sentidos que a sua trajetória de iniciação à docência, permite ao sujeito compreender a suas relações intersubjetivas que se desenvolvem no bojo da reflexão que faz sobre as práticas do exercício do magistério que desenvolve a partir do programa.

Neste cenário, a abordagem serviu para a verificação de um modelo interpretativo, em que as narrativas foram representativas, tanto para dizer sobre os conhecimentos adquiridos pelo sujeito, como também por terem se constituído num mecanismo de produção de novos conhecimentos acerca das trajetórias de formação dos envolvidos na pesquisa.

Pela condição de se introduzir o licenciando na realidade escolar, compreendida em sua temporalidade de ações produzidas por todo o ano letivo e não em períodos específicos, o programa introduziu um novo espírito na formação docente, favorecendo à licencianda a 
compreensão da escola em suas condições reais e temporais de funcionamento, visto que participa de ações que vão desde a jornada pedagógica, semanas de planejamento ao conselho final de classe, passando por todos os movimentos que a escola produz para dar conta de favorecer o ensino de qualidade e que atenda às necessidades de sua demanda local. A formação, nesta direção, não concebe a escola básica em um caráter de univocidade, como se todas elas fossem iguais e enfrentassem os mesmos problemas. As teorias e práticas assimiladas na universidade vão sendo testadas, avaliadas e discutidas, tendo em vista cada contexto específico da escola em que o licenciando atua.

Nesta seara, a Semântica em processo de formação, foi tendo a oportunidade de promover e desenvolver experiências metodológicas, tecnológicas e práticas no seio da escola, tendo a condição de refletir sobre cada procedimento, numa perspectiva de construção e reconstrução de sua habilidade para tornar-se professora. Tratou-se de uma compreensão de si e de seu processo formativo, evidenciado pela narrativa que produziu, e que lhe serviu também como elemento de formação.

Esse movimento fez aflorar um saber que se produziu nas experiências da licencianda nas relações com a sua formação universitária no curso de Letras, bem como com a escola básica, que se configurou como cenário de potencialização do processo formativo, ao lhe apresentar as condições reais, complexas e estruturais do ensino de Língua Portuguesa. Esse movimento tem uma relação direta com a produção da identidade docente, na medida em que todas as experiências pelas quais passa na escola marcam a forma de pensar e de agir da licencianda que, portanto, marcarão também as ações dela enquanto futura professora de português.

Evidenciou-se, ainda neste estudo, que o Pibid reconstrói a noção de lugar de produção identitária de sujeitos diversos. Para Semântica, a escola passou a ser o lugar em que ela pode compreender os vários movimentos e tempos transversalizados pelas possibilidades de atuação dos processos formativos, de que ela fez parte no programa. Tratou-se, pois, de ter a licencianda se inserido numa formação mais humanística, o que lhe permitiu compreender como é possível atuar na sala de aula nas condições reais em que o tempo passa a ser elemento determinante para a compreensão do que se deve fazer na docência em Língua Portuguesa.

Para a bolsista, a sua participação no programa consagrou-se como uma oportunidade de ter se inserido em todas as ações educativas que acontecem na escola e que são base do 
processo de formação do professor. Pelos resultados deste estudo, ratificou-se a ideia de Charlot (2005) que valoriza a formação do sujeito na construção de programas que permitam a apropriação de saberes oriundos da convivência com o outro. E o Pibid alargou o tempo de atuação da licencianda com os estudantes da escola básica, para garantir que a convivência seja uma condição de reflexão para atuação nos processos de ensino e Língua Portuguesa.

\section{REFERÊNCIAS}

BRASIL. Decreto no 7.219, de 24 de junho de 2010. Dispõe sobre o Programa Institucional de Bolsa de Iniciação à Docência - PIBID e dá outras providências. Diário Oficial [da] República Federativa do Brasil, Poder Executivo, Brasília, DF, 25 jun. 2010.

BRASIL. Lei no 11.502, de 11 de julho de 2007. Modifica as competências e a estrutura organizacional da fundação Coordenação de Aperfeiçoamento de Pessoal de Nível Superior CAPES, de que trata a Lei no 8.405, de 9 de janeiro de 1992; e altera as Leis no 8.405, de 9 de janeiro de 1992, e 11.273, de 6 de fevereiro de 2006, que autoriza a concessão de bolsas de estudo e de pesquisa a participantes de programas de formação inicial e continuada de professores para a educação básica. Diário Oficial [da] República Federativa do Brasil, Poder Executivo, Brasília, DF, 12 jul. 2007.

BRASIL. Ministério da Educação. Conselho Nacional de Educação / Câmara de Educação Superior. Resolução CNE/CES no 18, 13 de março de 2002. Estabelece as Diretrizes Curriculares para os Cursos de Letras. Diário Oficial [da] República Federativa do Brasil, Poder Executivo, Brasília, DF, 9 abr. 2002.

BRASIL. Portaria Normativa do Ministério da Educação no 38, de 13 de dezembro de 2007. Dispõe sobre o Programa de Bolsa Institucional à Docência - PIBID. Diário Oficial [da] República Federativa do Brasil, Poder Executivo, Brasília, DF, 13 dez. 2007.

CHARLOT, B. Relação com o saber, formação de professores e globalização: questões para a educação hoje. Porto Alegre: Artmed, 2005.

DELORY-MOMBERGER, C. A condição biográfica: ensaios sobre a narrativa de si na modernidade avançada. Natal: UFRN, 2012.

EREBEN, M. Biografía y autobiografía: el significado del método autobiográfico. Milano: Angelo Guerini e Associati, 1996.

JOSSO, M. C. Experiências de vida e formação. São Paulo: Cortez, 2004.

MIRANDA, N. S. Uma proposta curricular para a formação de professores de português. Boletim da Associação Brasileira de Linguística, Fortaleza, v. 25. p. 203-209, 2000. 
LISPECTOR, C. A hora da estrela. São Paulo: Record/Altaya, 1998.

NÓVOA, A.; FINGER, M. (Org.). O método (auto)biográfico e a formação. Natal: UFRN; São Paulo: Paulos, 2014.

OLIVEIRA, M. B. F. Discutindo a formação inicial de professores de língua materna: o processo de disciplinarização dos saberes de referência. In: CBLA, 6., 2004, São Paulo. Anais... São Paulo: PUC, 2004.

OLIVEIRA, M. B. F. Sala de Aula de língua e práticas cidadãs. Trabalhos de Linguística Aplicada, Campinas, v. 41, p. 65-74, 2003.

POSSENTI, S. Por que (não) ensinar gramática na escola. Campinas: Mercado de Letras, 2000.

RAMALHO, B. L. Estudo, caracterização e constituição de novas práticas formativas para a formação e profissionalização do (a) professor (a) do Ensino Fundamental. 1998. Projeto de Pesquisa Integrada - Programa de Pós-Graduação em Educação, Núcleo de Estudos e Pesquisas em Educação Básica, Natal, 1998.

REINALDO, M. A. G. M. Diversidade textual e ensino de leitura: atuação na formação do professor. Boletim da Associação Brasileira de Linguística, Fortaleza, v. 25, p. 157-171, 2000.

SILVA, F. O. Formação docente no Pibid: temporalidades, trajetórias e constituição identitária. 2017. 220 f. Tese (Doutorado em Educação) - Programa de Pós-Graduação em Educação, Universidade do Estado da Bahia, Salvador, 2017.

SOARES, M. O livro didático como fonte para a história da leitura e da formação do professor-leitor. In: MARINHO, M. (Org.). Ler e navegar: espaços e percursos da leitura. Campinas: Mercado de Letras: Associação de Leitura do Brasil, 2002. p. 31-76.

SOUZA, E. C. (Org.). Tempos, narrativas e ficções: a invenção de si. Porto Alegre: PUCRS; Salvador: UNEB, 2006.

TARDIF, M.; LESSARD, C.; LAHAYE, L. Os professores face ao saber: esboço de uma problemática do saber docente. Teoria \& Educação, Porto Alegre, n. 4, p. 215-233, 1991.

ZEICHNER, K.; LISTON, D. Teaching student teachers to reflect. Harvard Educational Review, Cambridge, v. 57, n. 1, p. 23-46, 1987.

Recebido em 12 de maio de 2017.

Aceito em 21 de maio de 2018.

Educação \& Formação, Fortaleza, v. 3, n. 8, p. 57-74, maio/ago. 2018

DOI: http://dx.doi.org/

http://seer.uece.br/redufor 